\title{
Amplitude e aspectos peculiares das desigualdades sociais na escola francesa*
}

Marie Duru-Bellat

Université de Bourgogne-IREDU-CNRS

\author{
Correspondência: \\ Marie Duru-Bellat \\ Université de Bourgogne \\ IREDU-CNRS - Pôle AAFE \\ BP 26513. F-21065 - Dijon - France \\ e-mail:marie.duru-bellat@wanadoo.fr
}

\section{Resumo}

A sociologia francesa denuncia com intensidade, desde o fim dos anos 1960, desigualdades sociais importantes e estáveis tanto no acesso aos diferentes níveis de ensino quanto ao sucesso escolar stricto sensu. Essa denúncia tomou a forma de uma teoria geral, elaborada por Bourdieu e Passeron, que faz dessas desigualdades sociais a resultante necessária do funcionamento da instituição escolar. E essa tese, não só de grande influência entre os sociólogos, como também amplamente difundida, contribuiu para nutrir um certo fatalismo, pois estabelece que a função mesma da escola é reproduzir e legitimar as desigualdades sociais. Por outro lado, ela produziu também um fluxo continuado de trabalhos que visam a fornecer-lhe confirmações empíricas. Este artigo apresenta, de maneira sintética, os principais resultados acumulados pela sociologia da educação francesa nessa direção, isto é, no que concerne às desigualdades sociais na escola. Na análise da gênese dessas desigualdades, distingue os mecanismos individuais e os mecanismos contextuais, assim como as desigualdades decorrentes do sucesso acadêmico stricto sensu, daqueles que resultam dos fenômenos de orientação e de escolhas escolares. A questão da responsabilidade própria da escola perante essas desigualdades é abordada em conclusão, indicando que o papel da escola em matéria de desigualdades sociais é ajustado por fatores estruturais, o que leva, quanto a teorias como a de Bourdieu, a relativizar um pouco sua importância, ou pelo menos a repensá-la profundamente.

\section{Palavras-chave}

Desigualdades sociais - Sucesso escolar - Carreira e escolha escolar - Efeitos do contexto escolar. 


\section{Amplitude and peculiar aspects of social inequalities in the French school*}

Marie Duru-Bellat

Université de Bourgogne-IREDU-CNRS
Contact:

Marie Duru-Bellat

Université de Bourgogne

IREDU-CNRS - Pôle AAFE

BP 26513. F-21065 - Dijon - France

e-mail:marie.dunu-bellat@wanadoo.fr

\begin{abstract}
French sociology denounces vehemently since the end of the 1960 s the important and standing social inequalities both in the access to the different levels of education and in school success stricto sensu. Such criticism has taken the form of a general theory put forward by Bourdieu and Passeron, in which such social inequalities are shown to be the necessary result of the functioning of the school institution. And this thesis, hugely influential not just among sociologists, but also more widely, has contributed to foster certain fatalism, since it establishes that the very function of school is to reproduce and legitimize the social inequalities. On the other hand, it has also produced a continuous flow of works aimed at providing it with empirical support. This article presents in a summarized way the main results accumulated by French sociology of education along these lines, that is, with respect to social inequalities at school. In the analysis of the genesis of those inequalities, the article distinguishes the individual mechanisms from the contextual ones, as well as inequalities that emerge from school success stricto sensu from those that result from the phenomena of school guidance and choices. The issue of the responsibility of the school itself with respect to those inequalities is considered as a conclusion to the text, indicating that the school's role as regards social inequalities is adjusted by structural factors, calling, as far as theories such as Bourdieu's are concerned, for a qualification of its importance or at least for its profound reconsideration.
\end{abstract}

\section{Keywords}

Social inequalities - School success - Career and school choice Effects of school context. 
Assim como na maioria dos países democráticos, a questão da igualdade nas escolas é de grande importância na França: espera-se que nela se avaliem as competências de cada um e, com base nisso, haja orientação profissional adequada, e isto de maneira imparcial, independentemente da origem social. No entanto, desde o final da década de 1960, a sociologia francesa tem denunciado vigorosamente a existência de desigualdades importantes e estáveis, tanto no acesso aos diferentes níveis de ensino quanto no êxito escolar stricto sensu. Essa denúncia assumiu a forma de uma teoria geral, elaborada por Bourdieu e Passeron (e apresentada em 1970 em La Reproduction), que fazia dessas desigualdades sociais a resultante necessária do funcionamento da instituição escolar. Essa tese, não só de grande influência entre os sociólogos, como também amplamente difundida, contribuiu para nutrir um certo fatalismo, pois estabelecia que a função mesma da escola era reproduzir e legitimar as desigualdades sociais. Mas produziu também um fluxo continuado de trabalhos que procuraram fornecer-lhe confirmações empíricas. Atualmente, a sociologia da educação é um dos campos mais dinâmicos da sociologia francesa. Ela traz à baila a amplitude das desigualdades sociais na escola ${ }^{1}$ e os processos que as engendram; permite também questionar as teorias da década de 1970 à luz de dados contemporâneos, pois é improvável que o papel da escola na reprodução das desigualdades seja hoje o mesmo que há trinta anos, na medida em que a escolarização sofreu uma expansão sem precedentes.

Apresentaremos sucessivamente o que hoje se sabe sobre desigualdades sociais na França, distinguindo entre desigualdades de ordem individual e de ordem contextual, antes de, em conclusão, questionarmos sobre as conseqüências teóricas e políticas dessa massa de conhecimento.

\section{Gênese e aspectos peculiares das desigualdades sociais}

A questão do modo como captar as desigualdades sociais é importante, uma vez que medidas diferentes produzirão imagens delas por vezes bastante diferentes umas das outras. 0 caminho mais comum consiste em comparar as taxas de acesso ou de desempenho, avaliadas em relação à origem social; as diferenças, variando por vezes de 1 para 2, surgem então entre as categorias extremas e seu vigor implica a conclusão de que as desigualdades sociais se produzem maciçamente. No entanto, outros parâmetros oferecem uma visão menos marcada. É o que se dá particularmente com os modelos de regressão multivariada, que estimam precisamente a porcentagem da variância do fenômeno explicado apenas pela origem social (taxa de acesso, escore), levando em conta um certo número de outras variáveis a ela associadas (e cujo efeito se mistura nas taxas brutas). Estima-se assim que, "tudo mais mantido inalterado" (levando em conta variáveis introduzidas na análise), a origem social explica geralmente $20 \%$ da variação do nível atingido no fim do ano, o que não é pouco, mas oferece sem dúvida uma visão menos implacável das desigualdades sociais.

\section{Desigualdades iniciais que se acumulam desde o primário}

Desde o ingresso na escola, o desenvolvimento cognitivo ou de linguagem da criança é marcado por desigualdades. Essas desigualdades são muito precoces. Os psicólogos mostram que, desde os 6 meses de idade, podem evidenciar-se correlações entre o desenvolvimento e a "qualidade" do ambiente da criança, captada por meio de índices variados do caráter estimulante desse ambiente (tais como o volume e a natureza dos estímulos de linguagem), correlação que se encontra também, um pouco enfraquecida, com esse índice muito global que é a profissão do pai (Reuchlin; Bacher,

1. E ainda mais porque, paralelamente a esse interesse pela questão das desigualdades sociais na escola, criou-se todo um dispositivo oficial de coleta de informacõos sobre a escolaridade dos alunos, notadamente sob a forma de pesquisas longitudinais periódicas — os chamados painéis de alunos - conduzidas pelo serviço estatístico do próprio Ministério da Educação. Esse serviço publica "Notas de informação" (aqui referidas como $\mathrm{NI} \mathrm{n}^{0} \mathrm{xX}$ ), disponíveis na página: www.education.gouv.fr/stateval. 
1989). Não é de admirar, portanto, se desigualdades sociais e de sexo se observem já nos primeiros anos da escola maternal. 2. Elas são particularmente nítidas, a partir da idade de 4 a 5 anos, na esfera verbal: a diferença entre as crianças cujo pai tem uma profissão superior ou média e os filhos de operários não-qualificados é de 1,2 desvio-padrão ${ }^{3}$ (Leroy-Audouin, 1993). Observam-se também desigualdades muito sensiveis entre crianças francesas e estrangeiras, em benefício das primeiras: 1,4 desvio-padrão na esfera verbal, 1 nas outras dimensões (portanto, a estruturação espacial ou a habilidade gráfica não são em nada menos discriminadores do que a linguagem). Comparativamente, as desigualdades entre os sexos são mais sutis: a vantagem das meninas é de 0,43 desvio-padrão na esfera verbal e um pouco menor nas demais dimensões cognitivas. Em todo caso, todos esses fatores não explicam senão pouco mais da terça parte da variação dos desempenhos aos 4-5 anos, o que não permite qualquer determinismo maciço.

0 fato de freqüentar mais ou menos cedo a "escola maternal" é igualmente importante. Essa instituição acolhe as crianças de menos de 6 anos (idade da escolaridade obrigatória), e a freqüência a ela é muito difundida atualmente: 99,6\% a freqüentam desde os 3 anos, $34,7 \%$ aos 2 anos. Hoje, é um pouco mais freqüente terem acesso ao maternal aos 2 anos de idade os filhos de agricultores e os filhos de docentes. lsso não deixa de ter importância na medida em que a freqüência ao maternal está associada a um melhor desenvolvimento da escolaridade no primário: assim, entre os alunos que ingressaram no primeiro ano da escola primária em 1997 (acompanhados graças a um painel do Ministério da Educação), a porcentagem de crianças que chegaram ao $3^{\circ}$ ano sem repetência é de $91 \%$ entre os que entraram no maternal aos 2 anos, $88 \%$ entre os que entraram aos 3 anos e 77\% entre os que entraram mais tarde (Caillé, 2001). Porém, esse efeito benéfico da pré-escolarização desde os 2 anos e não aos 3 anos é moderado (a desvan- tagem associada a uma pré-escolarização mais tardia, aos 4 ou 5 anos, é muito mais nítida); e é cada vez mais intenso tanto entre os filhos de ambiente privilegiado quanto entre os filhos de operários, particularmente os imigrantes. Apenas políticas visando a estas últimas categorias poderiam tornar a pré-escolarização precoce um instrumento de redução das desigualdades sociais, enquanto que, atualmente, ela reforça a vantagem de categorias como as dos filhos de docentes.

lsso é tanto mais importante pelo fato de que a partir do Curso Preparatório (CP, ou seja o $1^{\circ}$ ano do primário) as aprendizagens irão encadear-se cumulativamente: o que adquirimos no ano anterior constituirá o melhor preditor dos ganhos apresentados no fim do ano. Ora, desde o início do $\mathrm{CP},{ }^{4}$ a vantagem das crianças de ambiente privilegiado é particularmente clara nas competências que serão mobilizadas na aprendizagem da leitura (reconhecimento das letras, por exemplo), ou no domínio dos conceitos ligados ao tempo, sem dúvida porque essas capacidades foram objeto de aprendizagem familiar. Além disso, a desvantagem das crianças estrangeiras é particularmente acentuada em esferas como a compreensão oral ou o domínio de conceitos ligados ao tempo e ao espaço, o que provém de dificuldades de domínio da língua francesa.

2. 0 sistema escolar francês se organiza em uma seqüência que começa na creche, seguida pela escola maternal. Aos 6 anos a criança ingressa na escola, cursando o "primário", de cinco anos, e em seguida vai ao collège, correspondente, grosso modo, ao segundo ciclo do ensino fundamental no Brasil. Segue-se o lycée, que seria nosso ensino médio e que pode conduzir à realização de uma prova conhecida como baccalauréat, a qual avalia se 0 aluno alcançou o nível esperado para o ingresso no ensino superior. Nesta tradução, fizemos as correspondências possíveis e mais próximas com nosso sistema de ensino, mantendo contudo a nomenclatura francesa no caso do collège, do lycée e do bacalauréat. (N. T.)

3. Uma diferença de um desvio-padrão significa que cerca de $85 \%$ dos filhos de operários têm um nível inferior à média dos filhos de funcionários superiores, enquanto que se ambos os grupos fossem de igual nível, essa porcentagem seria de apenas $50 \%$. Em todo caso, a superposição entre as duas curvas é importante e a maioria dos membros de um grupo possui, pois, escores comparáveis aos do outro grupo.

4. Cf. Nota de Informação do Ministério da Educação Nacional (MEN) n. 9840, que apresenta os resultados do painel do primário, instituída em 1997/ 1998, e que acompanha 10 mil alunos que ingressaram no CP naquela data. 
Essas desigualdades iniciais terão influência determinante sobre o nível alcançado no final da classe de CP. Com base em provas de conhecimento e em modelos multivariados que explicam os desempenhos no final do $C P$, o nível no início do ano explica perto da metade da variação do nível atingido no fim do ano (Mingat, 1984; 1991). Como esses ganhos anteriores não deixam de ter relação com as características sociais da criança, estas encontramse em parte "retranscritas" sob a forma de ganhos escolares. Mesmo se, no decorrer de um dado ano, o efeito da origem social sobre o progresso parecer ser relativamente limitado, este efeito incorpora-se ao nível escolar que será o ingrediente principal do progresso no nível subseqüente. Em outras palavras, as desigualdades sociais que se instalaram em determinado nível terão efeito perene por intermédio do nível escolar atingido no início do ano seguinte.

lsto vale para os cinco anos do primário. Pode-se então construir um modelo que explica a probabilidade de ter passado por ele sem repetência, ${ }^{5}$ que resume de certo modo a escolaridade anterior (Vallet; Caille, 1996). Trata-se por certo de uma medida mínima da qualidade da escolaridade nesse nível, uma vez que apenas 25\% dos alunos merecem essa "distinção" (os restantes 75\%, os que não repetem de ano, permanecem muito desiguais quanto a seu nível de êxito). Nesse modelo, que traduz a acumulação das desigualdades a partir da primeira infância, as diferenças sociais são importantes e significativas: dadas as mesmas condições, o simples fato de ter um pai de profissão superior $^{6}$ e não um pai operário aumenta em $10,5 \%$ as chances de fazer um curso primário sem repetência, ou ainda o simples fato de ter uma mãe que possua pelo menos o baccalauréat (diploma de segundo grau), mais ainda do que um diploma de curso profissionalizante, faz as chances aumentarem para 11,4\%. A probabilidade de uma escolaridade primária sem repetência é também significativamente menor entre os meninos, e também entre as crianças que provêm de famílias com três ou mais filhos, ou ain- da (o efeito aqui é menos nítido) de uma família monoparental.

Em contraposição, essa pesquisa não revela desvantagem significativa dos alunos estrangeiros em relação aos alunos de mesmo ambiente social: se, em média, 54,3\% dos alunos estrangeiros não sofreram repetência no primário comparados aos 76,3\% dos alunos franceses, trata-se aqui inteiramente de um "efeito de estrutura”, ou seja, o efeito das diversas desvantagens sociais que eles acumulam (quando se considera a profissão ou o nível de instrução dos pais, o tamanho da família, etc). 0 fato de falar em casa outra língua que não o francês também não possui, por si só, efeito algum sobre o êxito. Somente crianças que passaram pelo menos três anos escolares fora da França encontram, tudo mais mantido inalterado, dificuldades reais.

Em suma, sobre o conjunto da escolaridade primária, parece que a vantagem inicial de que se beneficiam as crianças de ambiente privilegiado desde seu ingresso no maternal não é diminuída, enquanto a desvantagem relativa das crianças de origem estrangeira parece atenuar-se ligeiramente. Globalmente, não se pode dizer que as diferenças sociais se acentuam intensamente na escola maternal e na escola primária, mas sem dúvida uma escolarização de oito anos (em média) nessas instituições não consegue compensá-las. Verifica-se, pois, que existe uma lógica de acumulação.

\section{Desigualdades de exito e de orientação no secundário}

A disparidade do nível das crianças é chocante no ingresso ao $6^{\circ}$ ano (primeiro ano do collège, ou seja do secundário inferior): nas provas de conhecimento de começo de ano,

5. Apesar das pesquisas que demonstram sua pouca eficácia, a repetência continua muito difundida na França, a tal ponto que, aos 18 anos, cerca de um aluno a cada dois repetiu o ano pelo menos uma vez durante sua escolaridade.

6. Agrupam-se sob o título de "profissão superior" as profissões mais qualificadas: pessoal de saúde, engenheiros, pessoal de categoria mais alta nas empresas, docentes, etc., isto é, profissões que em geral exigem estudos universitários de pelo menos três anos. 
tanto em matemática quanto em francês, os 10\% de alunos mais fortes apresentam desempenho cerca de três vezes superior aos 10\% mais fracos (cf. N.l. n. 01.36). Novamente, o ambiente social está associado a essa disparidade dos níveis escolares (ainda que esteja longe de explicá-la inteiramente). Ora, o nível escolar inicial dos alunos tem evidentemente um grande peso: em modelos que analisam os progressos no correr do $6^{\circ}$ ano, 33\% do escore médio final explica-se (em francês e em matemática) apenas pelas características individuais do aluno (ou seja, mais do que nos níveis anteriores, o que revela uma acentuação dos efeitos de variáveis como a origem social); $67 \%$ do escore final explica-se pelo escore do início do $6^{\circ}$ ano $(0$ que atesta a influência crescente do nível inicial), e 70\% com as duas categorias de variáveis (pelo fato de sua grande superposição).

Além disso, durante os dois primeiros anos, os alunos inicialmente mais fortes progridem mais do que os alunos inicialmente mais fracos: pode-se, pois, falar de um certo elitismo do collège. Na medida em que os alunos de ambiente popular chegam ao collège com nível mais fraco, o elitismo do collège vai por si só aprofundar as desigualdades sociais, sem contar as novas desigualdades sociais ligadas especificamente aos progressos nesse nível. Foi possivel estimar que o collège "produzia" em dois anos mais desigualdades sociais de resultados do que toda a escolaridade anterior (Duru-Bellat; Mingat, 1993).

Por que essa aceleração das desigualdades entre alunos do collège? Certos traços do funcionamento pedagógico desse nível de ensino podem ser invocados, a título de hipótese. Pensa-se particularmente no conteúdo dos programas que, apesar de evoluções significativas, é em grande medida herança de uma época em que apenas uma faixa socialmente selecionada de alunos tinha acesso ao secundário. Porém, o aluno e sua família não se satisfazem em submeter-se a essa forma escolar somente. $\mathrm{Na}$ medida em que a estrutura pedagógica lhes oferece outras alternativas (bem mais do que no primário), desenvolvem no collège estratégias para tentar se beneficiarem do que lhes parecem condições de ensino mais favoráveis, desde a escolha de opções curricu-lares ou de orientação até a escolha do estabelecimento.

Se bem que, a partir de 1975, os cursos nesse primeiro estágio do secundário sejam os mesmos para todos, ${ }^{7}$ os pais devem escolher uma primeira língua no ingresso do $6^{\circ}$ ano e, dois anos depois, fazer outras opções curriculares. Essas escolhas revelam-se socialmente diversificadas. Tomemos o exemplo da escolha do latim (feita por 56\% dos filhos de docentes contra menos de 15\% dos filhos de operários não-qualificados). Sem dúvida, esses alunos (ou pelo menos suas famílias) são sinceramente atraídos pelas línguas antigas, mas de fato essa atração modela a composição escolar e social das classes (ou dos estabelecimentos) a que eles têm acesso, com a cumplicidade dos docentes, pois com base nas opções constituem-se classes homogêneas. Se se revela (voltaremos a tratar disso na segunda parte) que se progride mais nas "boas" classes, ou em determinados collèges, então as escolhas curriculares decorrentes dessas estratégias mais ou menos explícitas participam da gênese das desigualdades sociais.

Essa busca da "distinção" impregna igualmente as escolhas de orientação que o aluno deve fazer ao término do collège: ${ }^{8}$ elas constituem o terceiro mecanismo que, além das desigualdades sociais de progresso e de escolha de opções curriculares, concorre para o aumento das desigualdades sociais no collège. A orientação tem esse papel essencial porque, na França, as pessoas se empenham em seguir as deman-

7. A reforma Haby, aprovada em 1975 , suprime toda filière [diferentes ramos escolares, que conduzem a carreiras diferenciadas a partir de uma terminalidade também variada para o ensino secundário - N.T.] durante os quatro anos de collège: é o "collège único". Os programas são idênticos para todos, são proibidas as classes homogêneas, presume-se que os alunos freqüentam o collège de seu bairro.

8. 0 aluno pode ter acesso a um segundo ciclo longo, que conduz ao baccalauréat, ou a um segundo ciclo profissional curto que proporciona em dois anos qualificações de funcionários ou de operários qualificados (mas também podendo, com mais dois anos, levar a um baccalauréat profissional). 0 aluno pode também solicitar autorização para repetir a última série do collège, em geral para evitar uma orientação para o ensino profissional. 
das familiares. Ora, estas são variáveis conforme o nível econômico e cultural: quanto mais se é instruído ou de meio social elevado, mais se acredita na utilidade dos diplomas e se deseja que o filho obtenha um (cf. $\mathrm{Nl} \mathrm{n}^{\circ}$ 01.32).

Além disso, as demandas são marcadas por uma auto-seleção desigual segundo os ambientes sociais. Essa auto-seleção é de início escolar: quando o aluno é muito bom ou muito fraco, as intenções das famílias são respectiva e uniformemente ambiciosas ou modestas; mas as intenções dos alunos de desempenho médio caracterizam-se por grande diversidade, estruturada por idade (mesmo apresentando desempenho escolar idêntico, os alunos mais velhos manifestam intenções mais modestas) e sobretudo por ambiente social de origem. Ao final do $3^{\circ}$ ano, com menos de 9/20 de média no exame que confirma o fim do collège, $66 \%$ das famílias de funcionários superiores, contra 18\% das famílias operárias, demandam uma orientação em segundo ciclo longo (que conduz a um baccalauréat). As diferenças sociais são um pouco menos fortes entre os alunos médios: respectivamente $94 \%$ e $67 \%$ demandam ingresso no ciclo longo com notas entre 9 e 13. Uma categoria de alunos que representa um contingente expressivo é a dos alunos médios-fracos, cujas diferenças sociais na auto-seleção são mais nítidas. Em contraposição, deve ser assinalada a uniformidade das demandas entre os bons alunos, seja qual for o meio social (com mais de 96\% de demanda por um segundo ciclo longo quando as notas são superiores a 13).

Diante dessas demandas socialmente muito marcadas, os conselhos de classe (que reúnem os docentes e a administração escolar) tomam suas decisões de maneira essencialmente reativa (Roux; Davaillon, 2001): satisfazemse em contestar as escolhas que lhes pareçam irrealistas em vista do nível escolar, sem procurar descartar as escolhas prudentes dos jovens de ambiente popular. Com esse modo de funcionamento, os conselhos de classe legitimam as demandas socialmente diferenciadas e con- solidam as desigualdades sociais incorporadas nessas demandas.

Em contraposição, esse modo de funcionamento beneficia os jovens de origem estrangeira, cujas demandas de orientação são mais ambiciosas do que as das famílias francesas de ambiente social comparável (Vallet; Caille, 1996): com características sociais semelhantes, são em maior número a propor uma orientação de $2^{\circ}$ ciclo longo. Ao contrário, com desempenho escolar idêntico, a orientação não beneficia particularmente as meninas; suas melhores trajetórias escolares refletem, antes de mais nada, seu êxito acadêmico - sabendo que se observa certa resistência dos pais, no final do collège, em orientar suas filhas para os ramos profissionais (Roux; Davaillon, 2001).

Todos esses fatores que influem no desenrolar da escolaridade no collège são relativamente bem conhecidos, e a pesquisa é sobretudo preciosa quando avalia seus pesos respectivos. Assim, a partir de dados longitudinais coletados no correr da década de 1980 (DuruBellat; Jarousse; Mingat, 1993), foi possivel reconstituir a gênese da desigualdade de acesso ao lycée (em classe de $2^{\text {a }}$ série geral ou tecnológica) entre filhos de funcionários superiores e filhos de operários (sendo as taxas de acesso, nessa época, respectivamente de 87\% e 32\%). Esses dados certamente são antigos, mas oferecem ordens de grandeza interessantes: sobre esses 55 pontos de diferença, perto de 10 já estão presentes no ingresso no primário e se formaram, pois, anteriormente; durante o primário, formam-se 10 pontos de diferenças suplementares; restam pois 35 pontos, que vão se acumular durante os quatro anos de collège, o que indica incontestavelmente uma aceleração na gênese das desigualdades sociais no ensino secundário. Sobre esses 35 pontos, as desigualdades sociais de êxito só pesam mais do que as desigualdades de orientação (respectivamente 19 e 16 pontos). Se assim se confirma o peso capital do collège, parece também que na trajetória escolar como um todo, desde o maternal até o secundário, as desigualdades sociais de êxito 
que se acumulam ano após ano predominam sobre as desigualdades sociais que dizem respeito especificamente à orientação. Estas últimas, porém, estão longe de ser um fenômeno secundário: desde o nível do collège, e assim será cada vez mais à medida que avancem os cursos, não se pode considerar o encaminhamento do aluno e as diferenciações que o marcam como o reflexo meritocrático de ganhos mais ou menos satisfatórios.

\section{Estratégias e valor escolar acumulado no lycée e no ensino superior}

Os últimos vinte anos conheceram uma expansão excepcional da escolaridade no segundo ciclo longo (secundário superior): entre 1980 e 2000, a porcentagem de jovens que atingiram o nível de um baccalauréat (no conjunto de todas as vias) passou de $26 \%$ a $43 \%$, depois a $69 \%$ (valor que se manteve estável a partir dessa data). Nesse contexto, a obtenção do baccalauréat passou a ser menos rara e, conseqüentemente, menos desigual. Mas a ampliação do acesso ao nível do baccalauréat foi acompanhada de uma diversificação: cuidando da democratização, desenvolveram-se os baccalauréats tecnológicos e os baccalauréats profissionais. Os baccalauréats "gerais”, literários, econômicos ou científicos, mais antigos, que continuam a encarnar o arquétipo do baccalauréat, já não representam mais do que cerca da metade dos jovens que conseguem o título. A análise das desigualdades sociais no acesso ao baccalauréat deve, pois, à medida que ele se torna menos discriminatório, ser acrescida de uma análise das desigualdades na probabilidade de ter acesso a este ou aquele tipo de baccalauréat e a esta ou aquela especialidade.

Um primeiro ponto é que o acesso ao lycée continua marcado por diferenciações sociais. Dentre os alunos que ingressaram no $6^{\circ}$ ano em 1989, a porcentagem de alunos que ingressaram no lycée, para ali preparar em três anos um baccalauréat, varia de 90\%, entre os filhos de profissionais superiores e de docentes, a 42\%, para os filhos de operários. A diferença entre meninos e meninas, menos flagrante, é ainda assim bastante nítida, uma vez que ingressam no liceu 65\% de meninas contra 52\% de meninos. É preciso assinalar também o caráter muito popular do ramo que leva ao "baccalauréat profissional”, cujos alunos provêm do segundo ciclo tecnológico curto: ali, o peso dos filhos de operários é de 37,9\% (o de filhos de inativos e de desempregados é de 11,1\%) contra $21,2 \%$ (e 5,7\%) nos ramos que levam ao baccalauréat geral ou tecnológico.

No início da segunda série, os alunos devem fazer opções e, novamente, essas escolhas exprimem uma lógica de distinção social: por exemplo, a opção latim é com mais freqüência escolhida pelos melhores alunos e também pelos alunos dos ambientes sociais mais privilegiados, o que resulta em classes homogêneas, pois em geral os estabelecimentos agrupam os alunos segundo as opções. Certos estudos (cf., especialmente, Duru-Bellat; Jarousse; Solaux, 1997) mostram então um progresso significativamente melhor dos alunos que fizeram a opção latim (com um "plus" de quase meio desvio-padrão, o que é da maior importância), sem dúvida porque essas classes de latinistas agrupam os melhores alunos e... os melhores docentes, sabendo-se que os alunos que vão beneficiar-se dessa vantagem provêm mais freqüentemente de um ambiente abastado. Isso vem duplicar a vantagem desses alunos devido ao seu nível escolar mais elevado ao ingressar na $2^{\text {a }}$ série, o qual continua a ser o melhor preditor do nível atingido no fim do ano. Porém, no correr da $2^{\text {a }}$ série, os progressos são apenas levemente afetados pela origem social: como era previsível nesse estágio do curso, as variáveis escolares substituem em grande medida as variáveis sociais, e os filhos provindos de ambiente popular progridem apenas ligeiramente menos que os filhos de funcionários superiores de nível inicial e opções comparáveis.

No final da $2^{\text {a }}$ série, os alunos do lycée devem escolher uma especialidade de baccalauréat, que determina em grande medida sua 
orientação no ensino superior e suas perspectivas profissionais. 0 desempenho escolar é então determinante e orientar-se na direção de uma série final do tipo $S$ (científica) constitui indubitavelmente o que fazem os melhores alunos. Porém, para um desempenho escolar idêntico os vieses sociais são muito importantes: "tudo mais mantido inalterado", os filhos de profissionais superiores têm acesso em maior número a uma $1^{\text {a }} \mathrm{S}$. A esse viés específico acrescenta-se o efeito de um nível escolar melhor no final da $2^{\text {a }}$ série. Isso se explica em grande medida pelas demandas dos jovens e de suas famílias. Se os jovens, especialmente os rapazes, de meios sociais privilegiados são intensamente atraídos por uma orientação científica, que se sabe ser difícil mas que abre um máximo de caminhos, os jovens dos meios mais afastados da escola hesitam mais, mostram-se mais prudentes e mais sensiveis aos conselhos dos docentes, muitas vezes mais prudentes diante de sua oposição.

Em suma, no nível do lycée, as demandas familiares e sua firmeza relativamente à instituição parecem essenciais e os componentes estratégicos assumem peso cada vez maior. 0 desempenho escolar não deixa de ter importância e sua acumulação, por inércia, dá origem a constantes desigualdades, duplicadas pelos comportamentos estratégicos de escolha e de intenções de orientação.

No nível do ensino superior, mais ainda, a demanda mostra ser primordial e a autoseleção omnipresente, em suas dimensões escolares e sociais. Oficialmente, todo jovem que obteve o diploma de baccalauréat pode ter acesso à maioria das carreiras do ensino superior; só praticam uma seleção por currículo determinadas carreiras profissionais curtas e as classes especiais de lycée que preparam para os concursos de ingresso nas "grandes escolas" ${ }^{9}$ de engenharia ou de comércio. Essas escolas de elite são evidentemente preferidas pelos jovens de ambiente privilegiado. Assim, com um baccalauréat científico obtido sem atraso escolar (o que na França indica um êxito pelo menos honroso), mais da metade dos filhos de funcionários superiores (contra 30,5\% para as filhas) orientam-se em classes preparatórias para as "grandes escolas", o que não se dá senão com 21\% dos filhos de operários (e $9 \%$ das filhas). Os estudantes que entram na universidade são de origem social mais modesta (com exceção de certas carreiras como a medicina), do mesmo modo que os que buscam cursos de formação profissional curtos.

Em suma, a "paisagem" dos estudos superiores continua pois muito contrastada no plano sociológico, e o peso dos filhos de profissionais superiores e de professores continua extremamente desigual nas diferentes carreiras: enquanto seu peso na população na faixa de 20 a 24 anos é da ordem de 15\%, eles representam cerca de 33\% dos efetivos das carreiras universitárias, 14\% das classes que preparam para cursos de formação profissional curtos e 52\% das classes preparatórias para as grandes escolas. Se isolarmos as escolas de elite de maior prestígio (Politécnica, Escola Nacional de Administração, Altos Estudos Comerciais e as Escolas Normais Superiores), essa porcentagem atinge um nivel excepcional, pois supera os 81\% (Euriat; Thélot, 1995).

Essa cifra muito elevada ilustra a acumulação da excelência escolar a partir do início mesmo da escolaridade. Resulta também de todas as escolhas, as mais judiciosas, que a delimitaram. Por trás desses comportamentos, existe, entre os jovens mais bem dotados, antes de mais nada a busca de caminhos profissionais atraentes; mas há também a vontade de ter acesso a ambientes mais fechados, regidos por uma certa seleção, para se aproximar de jovens de um certo nível, numa perspectiva que mescla a preocupação de distinção e até mesmo de socialização.

Com respeito ao êxito nesse nível do ensino superior, é preciso assinalar que já não se observam desigualdades sociais de êxito

9. Na França, o ensino superior de excelência é oferecido nas chamadas "Grandes Escolas", de maior prestígio e tradição e o ensino nas universidades é considerado de menor qualidade. (N. T.) 
nitidas (com antecedentes escolares iniciais comparáveis), a não ser em algumas carreiras jurídicas ou literárias. Portanto, ao final de uma trajetória escolar em que cada qual foi selecionado de maneira diferente, "a desigualdade da seleção tende a reduzir progressivamente e, por vezes, a anular os efeitos da desigualdade diante da seleção" (Bourdieu; Passeron, 1970). Porém, a organização mesma dos cursos no ensino superior exige do estudante um "saber gerir" sua trajetória escolar de forma cada vez mais complexa. E é a orientação lato sensu (aí incluídas as reorientações em caso de fracassos, a escolha dos lugares de estudo, etc.) que se torna nesse estágio o fator determinante, o melhor até mesmo para explicar as diferenciações sociais. As desigualdades sociais, neste nível, constroem-se igualmente a partir do desencorajamento dos estudantes ou, ao contrário, de sua perseverança e de sua capacidade de vencer dificuldades e, secundariamente, sobre a convicção, socialmente construída, de que se pode obter êxito, mais do que sobre as competências intelectuais.

Concluindo, a observação das análises da escolaridade nos diferentes níveis revela vários pontos importantes. De início, as desigualdades entre crianças já se encontram presentes no ingresso à escola maternal e a escola não consegue opor-se a elas: ao contrário, elas se acumularão pouco a pouco no primário, e de maneira mais acentuada no início do collège. Esse fenômeno de "incorporação" da influência de origem social ao desempenho escolar, somado a uma seleção mais ou menos rigorosa (com os fenômenos correlatos de sub ou sobre-seleção), faz com que a partir do lycée e, mais ainda, no ensino superior, a origem social deixe de estar associada especificamente ao êxito. Nesse estágio, a diferenciação entre carreiras cria "microambientes" relativamente homogêneos socialmente, e as desigualdades sociais passam então a agir mais "entre-carreiras" do que “intra-carreiras”. Portanto, a origem social é ao mesmo tempo cada vez mais importante (ela introduz rupturas cada vez mais nítidas), mas ao mesmo tempo o desenvolvimento dos cursos mostra-se cada vez mais meritocrático, o que parece não deixar de ser importante em termos de legitimação das desigualdades.

Assim, os modos de influência do ambiente social de origem são plurais. No nível individual, basta que desde o ingresso na escola as crianças sejam mais ou menos bem preparadas para beneficiar-se dele. Basta que a cada ano pequenas desigualdades sociais de êxito venham agravar as diferenças de desempenho escolar, desempenho cuja inércia a seguir é grande. Basta também que, por ocasião de cada escolha, as estratégias venham acentuar ainda mais as diferenças decorrentes das desigualdades de desempenho escolar.

Não terá a escola responsabilidade nesse jogo em grande medida social? Ela pode, sem dúvida, sentir-se pouco responsável por essas desigualdades de escolha, em grande medida induzidas pela estrutura da sociedade (famílias desiguais buscam colocar seus filhos em posições desiguais). Isto posto, é ela, por sua organização, que dá mais ou menos importância a essas escolhas desiguais, e por meio desse fundamento orienta os alunos para ramos ou dispositivos particulares.

Evidentemente ela é mais diretamente cobrada pelas desigualdades de desempenho, ainda mais que a freqüência à escola não as atenua, ao contrário. 0 exame da maneira como as desigualdades de êxito e de trajetória se "fabricam" em contextos escolares, eles mesmos muito variados (assunto a que se dedica a segunda parte deste texto), esclarece os contornos dessa responsabilidade.

\section{o contexto escolar como vetor de desigualdades sociais}

0 sistema educacional francês costuma apresentar-se como único e, por isso mesmo, justo: ele ofereceria a todos os alunos conteúdos e condições de trabalho idênticas, sendo a uniformidade garantia da igualdade. Isso se traduzia até recentemente (as mudanças datam do início da 
década de 1980) por uma legislação muito centralizadora e pela dificuldade em aceitar a noção mesma de discriminação positiva. Paralelamente, entre os sociólogos, a predominância de teorias globais como as de Bourdieu, para quem a reprodução social presumivelmente operava de maneira implacável, quaisquer que fossem os contextos ou as épocas, levou a negligenciar o funcionamento concreto do sistema educacional. Foi preciso esperar os últimos vinte anos para que os pesquisadores explorassem precisamente o peso dos mecanismos de tipo contextual na gênese das desigualdades sociais de trajetórias escolares.

Atualmente sabe-se que: 1) o contexto

"faz diferença", isto é, que se aprende mais ou menos bem conforme os contextos (os professores, as escolas); 2) que os usuários mais atentos sabem disso, e buscam muito normalmente, e não sem êxito, conseguir para seus filhos o benefício das melhores condições de ensino. Do que resulta que desigualdades sociais decorrem especificamente do acesso a contextos escolares de qualidade desigual.

\section{Docentes e estabelecimentos desigualmente eficazes e eqüitativos}

As diferenças entre estabelecimentos, na orientação ou no êxito dos alunos, são há muito tempo conhecidas na França. Porém, a interpretação imediata muitas vezes as reduz às diferenças de tonalidade social entre estabelecimentos, elas próprias decorrentes da segregação social do habitat, uma vez que um sistema de "mapa escolar" presumivelmente obriga as famílias a pôr seus filhos na escola de seu bairro. ${ }^{10}$ Ao fazer isso, considera-se que a instituição escolar "herda" públicos dotados de características mais ou menos favoráveis ao êxito e que os resultados "refletem" essas desigualdades iniciais. Não há então efeito específico do contexto escolar, mas apenas efeitos de composição. Ora, hoje está demonstrado que para além de efeitos de composição, manifestam-se verdadeiros efeitos contextuais, ou seja, que o simples fato de freqüentar tal estabelecimento ou tal classe influi sobre a "sorte" escolar dos alunos.

Na França, a existência do "efeito escola” em matéria de orientação, para alunos estritamente comparáveis escolar e socialmente, está demonstrada desde a década de 1980. Em particular, em nível escolar comparável, um jovem oriundo de ambiente popular, escolarizado em um colégio de matiz social privilegiada, desenvolve um nível de aspiração escolar mais elevado do que se estivesse num estabelecimento mais popular, interferindo, pois, na composição social do público sobre o nível de aspiração que prevalece no estabelecimento, com conseqüências sobre as orientações que serão obtidas (Duru-Bellat; Mingat, 1988; Duru-Bellat et al., 2004).

Além disso, do mesmo modo que o processo de orientação, os desempenhos variam sensivelmente segundo os estabelecimentos. Essas diferenças não são espetaculares, mas estão longe de ser desprezíveis, uma vez que nos progressos que se dão durante um ano, no nível primário, a escola freqüentada pesa tanto e às vezes até mesmo mais do que a origem social, ainda que, no conjunto da trajetória escolar, a origem social acumule seus efeitos de maneira mais sistemática (o aluno pode mudar de contexto de ensino, mas não muda de ambiente familiar). No nível secundário, as estimativas feitas por Grisay (1997) revelam que "efeitos-escola" explicam cerca de 5\% da variação do nivel atingido no $3^{\circ}$ ano em matemática (um pouco menor é a cifra atingida em relação ao francês). Esses "efeitos-escola" são mais nítidos nos alunos mais fracos (são duas vezes mais importantes do que para a média dos alunos), enquanto, ao contrário, têm pouca importância para os alunos mais fortes.

Nos países anglo-saxões, a corrente chamada de "school effectiveness" produziu

10. Os perfis sociológicos dos estabelecimentos podem variar sensivelmente. Assim, no nível do collège, se se considera o peso das crianças oriundas dos ambientes mais modestos (que é de $44 \%$ no conjunto da população), ele é inferior a $22 \%$ nos $10 \%$ dos collèges mais privilegiados e superior a $68 \%$ nos $10 \%$ dos collèges mais populares. 
uma massa de resultados convergentes sobre os fatores pedagógicos próprios da escola associados a uma boa eficácia, particularmente com forte ascendência do diretor do estabelecimento, expectativas elevadas em relação aos alunos, um maior foco sobre as aprendizagens básicas, um clima de segurança e de ordem, avaliações freqüentes dos progressos dos alunos. Na França (Grisay, 1997), o papel do diretor do estabelecimento não se mostra com tanta nitidez. Mas encontra-se, em primeiro lugar, uma forte "exposição à aprendizagem”, com uma utilização ótima do tempo escolar (especialmente pouco tempo perdido para a gestão da disciplina) e pouco absenteísmo. Atuam igualmente expectativas elevadas da parte dos docentes e, portanto, uma acentuada valorização do trabalho escolar. Também intervêm positivamente a qualidade das relações entre docentes e alunos e da vida no colégio, a clareza das regras, um clima pacífico.

Mas os progressos dos alunos mostramse (ainda) mais sensíveis à classe do que ao estabelecimento freqüentado. Assim, nos primeiros níveis do primário, o "efeito classe" explica perto de $14 \%$ da variação dos progressos, um pouco mais em matemática do que em francês, contra, lembremos, cerca de 5\% para o "efeito-escola”. As estimativas são muito próximas no nível do collège, no qual os progressos realizados pelos alunos dependem bem mais da classe do que do colégio freqüentados (cf. Duru-Bellat; Mingat, 1988). Constatações convergentes são obtidas para o lycée (Felouzis, 1997). Do mesmo modo que para os "efeitos-estabelecimento", os efeitos de pertencer a determinada classe são mais sensíveis entre os alunos mais fracos.

Quer atuem no nível do estabelecimento ou da classe, esses diferenciais de eficácia (aliás, bem pouco acentuados na França, em comparação com os países vizinhos) têm conseqüências em matéria de desigualdades sociais entre alunos. Pois um dos fatores mais intensamente associados às desigualdades de progressos dos alunos (sabendo que esses fatores são relativamente similares no nível estabelecimento e no nível classe) é a composição social do público de alunos. Os estabelecimentos capazes de bom desempenho são, o mais das vezes, em média, os que acolhem um público provindo de um ambiente abastado, e, no nível individual, os alunos progridem tanto mais na medida em que freqüentam um estabelecimento cujo público é socialmente privilegiado, sabendo que esse efeito específico da tonalidade social permanece quantitativamente bastante fraco (Duru-Bellat; Mingat, 1988; Grisay, 1997; Duru-Bellat et al., 2004).

Do mesmo modo, no nível da classe, a composição do público da classe tem influência, ao mesmo tempo em sua dimensão escolar - academic mix - e em sua dimensão social - social mix. 0 modo como os diretores de estabelecimento compõem suas classes é, pois, importante. Ele pode assumir a forma oficialmente proibida (no collège, na França) e, portanto, freqüentemente tabu, da constituição das classes homogêneas, prática que estudos recentes revelam ser freqüentes no nível do collège (Duru-Bellat; Mingat, 1997). Ora, a constituição de classes hierarquizadas academica e, ao mesmo tempo, socialmente tem interferência sobre os progressos dos alunos do collège: eles progridem mais quando escolarizados numa classe de nível médio elevado. Além disso, os progressos são melhores quanto mais elevada for a heterogeneidade da classe (mas este efeito é menos intenso que o precedente). Finalmente e acima de tudo, a freqüência a uma classe heterogênea possui efeitos diversificados conforme o nível inicial dos alunos: os mais fracos "ganham" em freqüentar esse tipo de classe enquanto, ao contrário, os mais fortes perdem com isso. Mas o que ganham os fracos é cerca de duas vezes mais importante do que o que perdem os fortes: os mais fracos podem ganhar até meio desvio-padrão da distribuição das notas conforme estejam numa classe muito forte ou muito fraca, enquanto a perda dos fortes será no máximo da ordem de um quarto de desvio-padrão.

É evidentemente crucial compreender a relação que existe, no nível da classe e no ní- 
vel do estabelecimento, entre a composição social e os progressos dos alunos. Uma primeira pista explicativa consiste em invocar a qualidade desigual da oferta escolar. Conhecem-se muito mal, na França, as desigualdades de dotação em pessoal ou, mais amplamente, em recursos segundo as zonas geográficas. Hoje em dia não há nada que nos permita afirmar que os recursos alocados seriam sistematicamente mais restritos nas zonas populares, ainda mais porque, a partir da década de 1980, o Estado pratica uma certa discriminação positiva. Mas isto não controla obrigatoriamente os recursos que mostram ser os mais eficazes. Assim, o tamanho das classes é efetivamente mais restrito nas Zonas de Educação Prioritária (ZEP) quase dois alunos a menos - mas isso interfere pouco na aprendizagem. Em contraposição, ali se concentram os professores menos experimentados (muitas vezes isto também se dá nas classes de nível fraco), o que constitui uma característica associada em média a uma menor eficácia. A própria oferta é muitas vezes um fator de reforço das desigualdades. Assim, nas zonas mais populares, os ramos de exclusão precoce, tais como as classes destinadas especificamente aos alunos com dificuldades, são mais difundidos e os alunos de ambiente popular irão preencher esses ramos que os distanciam da pretensão de estudos longos. Ao contrário, as classes preparatórias para as "Grandes Escolas" são com mais freqüência implantadas nos lycées freqüentados por alunos de ambiente privilegiado. Os alunos, no contexto geográfico a que pertencem, submetem-se, portanto, à oferta disponível, e esta é uma faceta das desigualdades sociais.

Mas se os indivíduos se submetem ao contexto, este é também "fabricado" pela reunião de indivíduos, uma vez que são as características sociais e escolares dos alunos que, em interação com os docentes, contribuem para compor um ambiente de qualidade desigual. 0 contexto são os colegas com quem se encontra, o "recurso" que eles constituem, o clima que deles decorre nos estabelecimentos e nas classes, as práticas pedagógicas que vão ser consideradas possíveis ou, ao contrário, mais difíceis de serem postas em ação.

\section{Dinâmicas sociais que agravam as diferenças}

Tanto no nível da classe quanto no nível do estabelecimento, sabe-se que, segundo o nível acadêmico e a composição social do público, a instrução proporcionada varia em quantidade e em qualidade, porque os docentes adaptam as práticas pedagógicas em função do suposto nível dos alunos. Em certos casos, a preocupação de adaptação do docente pode traduzir-se por uma diversificação não somente dos meios oferecidos ao aluno para atingir os objetivos, mas também dos próprios objetivos, que são mais modestos em relação aos alunos mais fracos. Nas escolas privilegiadas, estando a cultura e as normas de conduta dos alunos mais próximas das expectativas da instituição, os docentes podem ter um nivel de exigência mais elevado e cobrir melhor os programas. Por exemplo, desde o segundo ano do primário, cerca de três quartas partes dos professores das escolas mais populares julgam os programas irrealistas, o que não se dá senão com uma terça parte dos professores das escolas mais privilegiadas (Duru-Bellat et al., 2004). Do mesmo modo, no nível do collège (Meuret, 1995), nos estabelecimentos populares, a exposição à aprendizagem é menos intensa, a cobertura dos programas é menos completa e a disciplina menos assegurada.

Sobre este último ponto, a observação da prática dos docentes em ambiente desfavorecido mostra em que medida as tarefas de manutenção da ordem invadem o tempo disponível para as atividades de ensino (Van Zanten, 2000). Além desses comportamentos adaptativos objetivos, os docentes desenvolvem expectativas inevitavelmente estereotipadas, particularmente com uma tendência sistemática a subestimar o nivel de competência das crianças provindas de ambiente popular. É comprovado, pois, que so- 
bre esses dois parâmetros fundamentais da eficácia que são, de um lado, a gestão dos conteúdos e do tempo e, de outro, as expectativas, as práticas que prevalecem em ambiente popular são, muito freqüentemente, menos favoráveis.

De maneira geral, todas as maneiras de agir dos docentes elaboram-se no seio de seu contexto de exercício; elas integram as representações que constroem de seu público, de seus ganhos ou de suas carências, e de seus interesses (Van Zanten, 2000). A preocupação em adaptar-se aos alunos é compreensível e mesmo necessária. Pode, porém, ter efeitos perversos. Os docentes, ao se esforçarem em propor conteúdos adaptados à diversidade de bagagens e interesses culturais dos alunos, muitas vezes reforçam essas desigualdades iniciais.

Finalmente, no currículo real (aquele que se mostra possivel de executar) que prevalece nos estabelecimentos, o que existe é uma relação de duplo sentido: o currículo real resulta de uma negociação entre os alunos tais como são, tais como obrigam os docentes a adaptarse a eles, e aquilo que lhes é proposto, para que no geral a situação seja suportável. Parte da eficácia dessas escolas é, pois, de certo modo, "trazida" pelos alunos, em todo caso em grande medida dependente do "school mix" que torna possíveis as práticas pedagógicas as quais constituem os vetores proximais da eficácia.

0 que se passa no dia-a-dia entre os alunos constitui, pois, uma segunda pista, igualmente importante, para compreender por que um público majoritariamente popular compõe de fato um meio menos propício às aprendizagens escolares. Diversos fatores atuam neste caso. De início, é preciso lembrar que as expectativas positivas dos docentes são percebidas pelos alunos e não deixam de ter sua eficácia própria: uma expectativa positiva estimula, ao passo que a antecipação do fracasso pode ter como efeito provocá-lo (segundo a lógica da "profecia auto-realizadora”, ilustrada, na esfera escolar, por abundante literatura; para uma síntese, cf. Broophy ; Good, 1986). Os alunos desenvolvem igualmente normas de grupo, e cer- tas observações sugerem que, nas classes populares, um certo nível de indisciplina é mais considerado como normal (Duru-Bellat et al., 2004).

Além dessa questão das normas do grupo, toda uma parte do efeito do "school mix" decorreria das interações entre alunos (seria um “peer effect”), sendo essas interações inegavelmente estimulantes segundo os diferenciais de recursos entre os alunos. Assim, os alunos provindos de ambiente popular poderiam, em contato com colegas dotados de recursos culturais mais importantes, não somente ser dissuadidos, em vista dessa vizinhança cotidiana, de desenvolver comportamentos escolares desviantes ou de retração, mas também “aprender” verdadeiramente com seu contato (Thrupp,1999).

Em suma, os ambientes contrastantes que constituem os estabelecimentos de público socialmente tipificado, quer de tipo privilegiado, quer de tipo desfavorecido, ou, ainda, as classes homogêneas, constituem "ambientes" de aprendizagem e de socialização cuja composição social constitui componente essencial, devido à dinâmica psicossocial que ali se instala (entre docentes e alunos, e entre alunos). Os efeitos de contexto enrijecem as desigualdades sociais porque os alunos mais privilegiados beneficiam-se sistematicamente dos contextos mais eficazes, ou menos seletivos, e, mais ainda, contribuem para torná-los mais eficazes ou menos seletivos pelo fato mesmo de sua agregação e das reações à intenção adaptativa dos docentes. A verdade é que em conseqüência de os alunos mais privilegiados se beneficiarem, em geral e em maior número, das melhores condições de ensino, torna-se difícil dissociar os trunfos que os alunos tiram de seu ambiente social e os que tiram de seu contexto de escolarização. A ação do meio social sobre o êxito e a trajetória escolar da criança é, pois, em grande parte indireta, transitando pelo acesso a um contexto escolar de qualidade desigual (e não, pelo menos não unicamente, por mecanismos individuais do tipo "herança cultural"). Mas o contexto escolar é ele próprio construído por estratégias dos atores, que se mostram essenciais na criação das desigualdades de contexto. 


\section{Familias desiguais em face de desigualdades da oferta}

As famílias mais próximas da escola percebem as desigualdades nas "oportunidades de aprender" ou na qualidade da vida escolar que os estabelecimentos oferecem a seus filhos. Se se demonstra que os colégios freqüentados majoritariamente por uma população abastada são ao mesmo tempo mais eficazes, menos seletivos e oferecem um clima mais calmo, então é racional que as famílias busquem esse tipo de estabelecimento, com chances desiguais de lá chegar. As diversas pesquisas sobre as razões invocadas pelas famílias para a escolha de um estabelecimento (resumidas em Duru-Bellat, 2001) mostram que, se elas evocam abertamente a qualidade acadêmica da escola, a hegemonia das considerações escolares está longe de ser total. Igualmente importante é o fato de os pais levarem em conta a percepção que têm do clima da escola, da qualidade de seus docentes e do bem-estar da criança. Isto posto, na falta de dados objetivos sobre essas questões, a apreensão da "qualidade" da escola deduz-se muitas vezes da "qualidade" aparente de seu público e, portanto, das características sociais, e às vezes étnicas, dos alunos. Portanto, tanto se escolhem os colegas da criança, este ou aquele "school mix", quanto uma escola mais ou menos eficaz.

Num sistema de mapa escolar, em que os estabelecimentos recrutam sobre uma base geográfica, a escolha do domicílio permite a certas famílias situar-se sem dificuldade na vizinhança dos estabelecimentos que pretendem conseguir, sendo que essa possibilidade de escolher seu lugar de domicílio é, ela própria, uma componente das desigualdades sociais. 0 mapa escolar, portanto, ratifica essas desigualdades residenciais. A partir de 1983, acrescentou-se um certo "abrandamento do mapa escolar”. Certamente, o fenômeno de substituição continua de amplitude limitada, uma vez que menos de $10 \%$ dos alunos de $6^{\circ}$ ano freqüentam um outro colégio público que não de seu setor, proporção essa que se mantém estável há uma década (cf. $\mathrm{Nl} \mathrm{n}^{\circ}$ 01.42). Mas essa cifra oculta disparidades importantes entre as zonas rurais (onde ela é próxima de 5\%) e as grandes aglomerações (onde muitas vezes supera 10\%, em certas zonas até mesmo 20\%). E, sobretudo, os pais que escolhem um estabelecimento público ou o ensino privado, ou seja, no total cerca de $20 \%$ dos pais, são de ambiente social bem típico: se o privado é escolhido sobretudo pelos profissionais independentes, a escolha no seio do público é antes de mais nada feita pelos docentes e mais amplamente por funcionários públicos. Em suma, todas as famílias parecem ser bem conscientes da aposta que constitui o acesso a esta ou àquela "oferta" escolar e, notadamente a seu "school mix".

Essas estratégias familiares manifestam-se também no seio mesmo dos estabelecimentos. As famílias mais bem informadas não só intervêm por vezes diretamente na vida da escola. Uma vez que estão ao mesmo tempo conscientes dos "problemas” locais mas não podem abandonar o bairro, acionam estratégias de "colonização" (Van Zanten, 2001) para acomodar seu filho em um contexto preservado: isso passa por certas escolhas de opções curriculares, mas também por intervenções diretas junto aos diretores do estabelecimento para a designação de seu filho para esta ou aquela classe, ou a criação de opções particulares cuja única função é agrupar os alunos que se pretende "proteger" dos demais. Assim, as famílias (pelo menos algumas delas, aquelas cujos filhos são de bom nível escolar, e que são também as mais influentes no meio escolar) têm interesse em que seu filho esteja numa "boa" classe (uma vez que se progride mais quanto mais elevado seja o nível médio da classe), e que o estabelecimento faça classes homogêneas. De fato, essas estratégias parentais parecem conformes aos interesses privados dos pais de bons alunos e globalmente muito racionais. Divergem, porém, do que parece ser o interesse geral. Pois em nivel global, se se levam em conta os ganhos escolares de toda uma faixa etária, as classes heterogêneas é que se mostram mais "produtivas", maximizando os progressos dos mais fracos sem onerar proporcional- 
mente o progresso dos mais fortes. Mas os pais dos alunos fracos, que têm todo interesse nas classes heterogêneas, são nitidamente menos influentes. Há, pois, interesses divergentes que se exprimem na escola: as famílias lutam, com armas desiguais, para apropriarem-se dos melhores recursos escolares e para colocar seus filhos em melhor situação em relação àqueles que serão seus concorrentes no acesso às melhores carreiras e in fine às melhores posições sociais.

Concluindo, os contextos escolares, a tonalidade social e os recursos educativos que os acompanham são em grande medida impostos às famílias em função de sua situação geográfica (jamais neutra socialmente). Compreende-se, porém, que os pais, que buscam "normalmente" controlar suas condições de vida, procurem também oferecer a seus filhos o meio escolar mais agradável e mais produtivo possivel, pois o que se pode ganhar com uma escolaridade bem sucedida é muito importante. As famílias participam, portanto, ativa mas desigualmente da criação e da preservação das "condições de contexto" que lhes sejam as mais favoráveis.

\section{Conclusão}

Os diversos mecanismos que dão origem às desigualdades sociais de trajetória - caráter cumulativo das desigualdades iniciais, auto-seleção diferenciada nos patamares de orientação, contextos de qualidade divergente, etc. - são relativamente estáveis. Com a expansão da escolarização, as desigualdades sociais tendem no entanto a manifestar-se cada vez mais tar-diamente (Duru-Bellat; Kieffer, 2000; Merle, 2002): os níveis hoje atingidos por todos (o fim do collège, por exemplo) encontram-se ipso facto democratizados, mas as desigualdades manifestam-se para além disso (no ingresso ao lycée) e de maneira mais qualitativa (escolha de uma série de baccalauréat e depois de uma orientação para o ensino superior).0 processo de democratização é, pois, acompanhado duma disputa prévia, uma vez que famílias desiguais buscam situar seus filhos o melhor possivel na competição por posições desiguais.

Não é pois de admirar que uma certa democratização da educação quase não tenha tido impacto sobre os fenômenos de reprodução social: certamente, a imobilidade social entre gerações é hoje um pouco menos forte que no início do século XX, e o desenvolvimento da instrução teve um papel quanto a isso, mas essa evolução não tem medida comum com o desenvolvimento da escolaridade (Vallet, 1999). Em outras palavras, a diminuição da desigualdade das oportunidades escolares foi mais nítida do que a diminuição da desigualdade das oportunidades sociais. As evoluções contemporâneas corroboram, pois, as predições teóricas de Boudon (1973), ou seja, que a evolução da desigualdade das oportunidades sociais não necessariamente acompanha a evolução da desigualdade das oportunidades escolares.

Com efeito, quaisquer que sejam suas características pessoais, os indivíduos inserem-se numa sociedade em que os "postos" estão definidos, e se a escola é um meio relativamente eficaz para atingir os melhores postos, a definição destes (e mais amplamente a estrati-ficação social e o nível das desigualdades) não é fundamentalmente de sua competência. Intervêm notadamente coerções estruturais, em particular a relação entre o número de diplomados e o volume de "postos" a ocupar no espaço econômico. A evolução recente desses parâmetros atribui um relevo especial a essa questão. Se, como se observa na França nestes últimos vinte anos (Forsé, 2001), a estrutura social se desloca menos rapidamente para o alto que a dos níveis de educação, o ajuste se fará à custa de uma desvalorização dos diplomas.

0 papel da escola em matéria de desigualdades sociais é, pois, ajustado por fatores estruturais, o que leva, sem dúvida, quanto a teorias como a de Bourdieu, a relativizar um pouco sua importância, ou pelo menos a repensá-la profundamente. 


\section{Referências bibliográficas}

BOUDON, R. L’inegalité des chances: la mobilité sociale dans les sociétés industrielles. Paris: Colin. 1973.

BOURDIEU, P.; PASSERON, J-C. La reproduction: elements pour une théorie du système d'enseignement. Paris: Ed. de Minuit. 1970.

BROPHY, J.E. ; GOOD, T. L. Teacher behaviour and student achievement. In: WITTROCK, M.C. (Org.). Handbook of Research on Teaching. Nova York: Macmillan. 1986. p. 328-275.

DURU-BELLAT, M. Controverses autour du choix de l'école: les leçons de l'étranger. L'Orientation Scolaire e Professionelle, v. 30, p. 131-153. 2001.

Les inégalités sociales à l'école: genèse et mythes. Paris: PUF. 2002.

DURU-BELLAT, M.; JAROUSSE, J.P.; MINGAT, A. Les scolarités de la maternelle au lycée. Revue Française de Sociologie, v. 34 , p. 43-60. 1993.

DURU-BELLAT, M.; JAROUSSE, J.P.; SOLAUX, G. S'orienter et élaborer un projet au sein d'un système hiérarchisé, une infonction paradoxale? L'Orientation Scolaire et Professionelle, v. 26, p. 459-482. 1997.

DURU-BELLAT, M.; KIEFFER, A. Inequalities in educational opportunities in France: educational expansion, democratization or shifting barriers? Journal of Education Policy, v. 15, n. 3, p. 333-352. 2000.

DURU-BELLAT, M. et al. Tonalité social du contexte et expérience scolaire des elèves au lycée et à l'école primaire. Revue Française de Sociologie, v. 45, n. 3, p. 441-468. 2004.

DURU-BELLAT, M.; MINGAT, A. Le déroulement de la scolarité au collège: le contexte «fait des differences". Revue Française de Sociologie, v. 29, p. 649-666. 1988.

Pour une approche analytique du fonctionnement du système éducatif. Parais: PUF. 1993.

La constitution des classes de niveau par les collèges: les effets pervers d'une pratique à visée égalisatrice. Revue Française de Sociologie, v. 38, p. 759-790. 1997.

EURIAT, M.; THÉLOT, C. Le recrutement social de l'élite scolaire depuis 40 ans. Education et Formations, v. 41, p. 3-21. 1995.

FELOUZIS, G. L'éfficacité des enseignants. Paris: PUF. 1997.

FORSÉ, M. L'évolution des chances sociales e scolaires en France au cours des quinze dernières années. In: BOUDON, R. et al. (Org.). Ecole et société: les paradoxes de la democratie. Paris: PUF. 2001. p. 171-186.

GRISAY, A. L'évolution des acquis cognitifs e socio-affectifs des élèves au cours de années de collège. Dossiers Education et Formation, v. 88. 1997.

LEROY-AUDOUIN, C. L'école maternelle, entre la diversité des élèves e la continuité éducative. 1993. Thése (Doctorat) Université de Bourgogne, Dijon. 1993.

MERLE, P. La democratisation de l'enseignement. Paris: La Découverte. 2002.

MEURET, D. Distribution sociale des facteurs d'efficacité des collèges. In: BESSE, J-M et al., Ecole efficace: de l'école primaire à I'Université. AFAE, Paris: Colin, 1995. p. 81-91.

MINGAT, A. Les acquisitions scolaires au CP: les origines des différences. Revue Française de Pédagogie, v.69, p. 49-62. 1984.

Expliquer la variété des acquisitions scolaires au CP: les rôles de l'enfant, la famille et l'école. Revue Française de

Pédagogie, v. 95, p. 47-63. 1991

REUCHLIN, M.; BACHER, F. Les différences individuelles dans le développement cognitif de l'enfant. Paris: PUF. 1989. 
ROUX, S.; DAVAILLON, A. Le processus d'orientation en fin de 3º. Education et Formations, 60, 41-54. 2001.

THRUPP, M. Schools making a difference: let's be realistic! Buckingham: Open University Press. 1999.

VALLET, L-A. Quarante ans de mobilité sociale. Revue Française de Sociologie, v. 40, n. 1, p. 5-64. 1999.

VALLET, L-A.; CAILLE, J.P. Les élèves étrangers ou issus de l'immigration dans l'école et le collège français. Dossiers Education et Formations, v. 67. 1996.

VAN ZANTEN, A. Massification et régulation des établissements d'enseignement: le traitement des publics en difficulté dans les collèges de banlieue. L'Année Sociologique, v. 50, p. 409-436. 2000.

L'école de la périphérie. Paris: PUF. 2001.

Recebido em 20.12.04

Aprovado em 03.03.05

Marie Duru-Bellat é professora em Ciências da Educação na Université de Bourgogne (França) e pesquisadora na REDUCNRS (Institut de Recherche en Education). 